\title{
Sự tác động của các đặc điểm tính cách đến ý định đầu tư tài chính cá nhân: Một nghiên cứu trên thế hệ $Y$
}

\section{The impact of Big-five personality traits on investment intentions: Study on generation $\mathbf{Y}$}

\author{
Trần Ngọc Hưng ${ }^{*}$, Dương Như Hùng ${ }^{2}$, \\ Nguyễn Tường $\mathrm{Nam}^{3}$, Trương Ngọc Anh Vũ ${ }^{4}$ \\ ${ }^{1}$ Công ty cổ phần tập đoàn năng lượng Tuấn Ân, Việt Nam \\ ${ }^{2}$ Trường Đại học Bách khoa Thành phố Hồ Chí Minh, Việt Nam \\ ${ }^{3}$ Trường Cao đẳng Kinh Tế Thành phố Hồ Chí Minh, Việt Nam \\ ${ }^{4}$ Trường Đại học Mở Thành phố Hồ Chí Minh, Việt Nam \\ *Tác giả liên hệ, Email: vu.tna@ou.edu.vn
}

THÔNG TIN

DOI: $10.46223 / \mathrm{HCMCOUJS.}$ econ.vi.15.3.1331.2020

Ngày nhận: 05/03/2020

Ngày nhận lại: 09/04/2020

Duyệt đăng: 20/04/2020

\section{Tù khóa:}

đặc điểm tính cách, thế hệ Y, thái độ đối với rủi ro tài chính, ý định đầu tư tài chính cá nhân

Keywords:

personality characteristic, generation $\mathrm{Y}$, attitude toward financial risks, intention to invest in the personal finance

\section{TÓM TÁT}


conclusion, the paper may be useful for analysts or finance companies to better understand the behavior of individual finance investment of gen Y Vietnamese.

\section{Giới thiệu}

Theo Tổng cục Thống kê (Bộ Kế hoạch và Đầu tư), năm 2019 Việt Nam có tốc độ tăng tổng sản phẩm trong nước (GDP) ước tính tăng 7,02\% so với năm 2018. Đặc biệt, hiệu quả tín dụng đối với tăng trưởng kinh tế được cải thiện. Tốc độ tăng tín dụng cần thiết cho $1 \%$ tăng trưởng kinh tế đã giảm từ trên $2,2 \%$ năm 2017 xuống mức bình quân 1,4\% năm 2019. Tăng trưởng vốn huy động từ thị trường chứng khoán thông qua phát hành trái phiếu doanh nghiệp, cổ phiếu bổ sung vốn đạt mức tăng trưởng ấn tượng với hơn $33 \%$. Như vậy đi cùng đà tăng trưởng ổn định trên 5\% từ năm 2012 đến năm 2019 thì lượng nguồn vốn đầu tư cá nhân dồi dào đã góp một phần hết sức quan trọng vào việc phát triển hoạt động kinh tế và hoạt động đầu tư.

Đầu năm 2019 Thủ tướng Chính phủ Nguyễn Xuân Phúc ban hành Đề án tái cấu trúc thị trường chứng khoán Việt Nam, trong đó đặt mục tiêu tăng số lượng nhà đầu tư lên $3 \%$ dân số, tương đương với gần 3 triệu tài khoản đến năm 2020 và nâng lên 5\% đến năm 2025 (Lam Phong, 2019). Để tăng số lượng cá nhân đầu tư tài chính, các nhà môi giới, các công ty tài chính không thể không chú ý đến thế hệ Y ở Việt Nam, thế hệ này đang được quan tâm đến rất nhiều vì sẽ là thế hệ chủ chốt trong lực lượng lao động chính toàn cầu ( $32 \%$ dân số thế giới và $35 \%$ dân số Việt Nam) (Nielsen, 2016). Theo Miller và Washington (2009) thế hệ Y hay có tên gọi khác là Millennials là những người sinh từ năm 1977 đến 2000. Mothersbaugh và Hawkins (2016) nêu lên các yếu tố làm cho thế hệ $\mathrm{Y}$ có nét riêng so với các thế hệ khác bao gồm: sử dụng công nghệ, thích âm nhạc và văn hoá pop, có tính khoan dung, thông minh và yêu thích thời trang. Như vậy với thực trạng số lượng nhà đầu tư hiện hữu và tiềm năng ở thế hệ Y là không nhỏ, với nhiều đặc điểm riêng biệt đồng thời là thế hệ tương lai của đất nước. Do đó, yêu cầu cần thiết để có cái nhìn tổng quan và rõ nét về hành vi, ý định đầu tư tài chính cá nhân của thế hệ này.

Tversky và Kahneman (1974) đã chỉ ra rằng không phải lúc nào các nhà đầu tư cũng thực hiện các phân tích thống kê phức tạp trong quá trình ra quyết định, mà họ lại dựa trên các phán đoán đơn giản để dự đoán phần lợi ích sẽ thu về được. Theo nghiên cứu của Nga và Yien (2013), một nhà đầu tư cá nhân có sự mơ hồ và không chắc chắn trong việc ra quyết định thường đưa ra quyết định dựa trên những thiên lệch về nhận thức. Cảm xúc, các đặc điểm tính cách, cùng với các tác động bên ngoài môi trường, ảnh hưởng đến quá trình ra quyết định và nhận thức của các nhà đầu tư. Theo nghiên cứu của Enescu và Enescu (2009) thì mỗi nhà đầu tư có những đặc điểm cá nhân và kỳ vọng khác nhau, vì thế họ có thái độ đối với rủi ro tài chính và mục tiêu tài chính khác nhau. Các yếu tố tâm lý đóng vai trò quan trọng trong việc xác định các hành vi đầu tư của các cá nhân. Quyết định đầu tư luôn đi kèm với những rủi ro vốn có hoặc tiềm ẩn. Nhận thức về rủi ro của một cá nhân phụ thuộc vào nhiều yếu tố khác nhau, một trong số đó là các đặc điểm tính cách của từng cá nhân. Các đặc điểm tính cách của các cá nhân sẽ ảnh hưởng đến thái độ rủi ro, và ảnh hưởng đến ý định đầu tư của họ.

Từ các yếu tố trên, nghiên cứu: "Sự tác động của các đặc điểm tính cách đến ý định đầu tư tài chính cá nhân, một nghiên cứu trên thế hệ Y" được thực hiện nhằm đánh giá tác động các đặc điểm tính cách của các cá nhân thế hệ Y lên thái độ rủi ro tài chính và đầu tư tài chính, để từ đó đưa ra nhận định đầu tư tài chính cá nhân phù hợp dựa trên các đặc điểm tính cách và thái độ đối với rủi ro của các cá nhân tại Việt Nam. 


\section{Cơ sở lý thuyết, các giả thuyết và mô hình nghiên cứu}

\subsection{Cơ sở lý thuyết}

Costa và McCrae (1992) đã mô tả đặc điểm tính cách dưới dạng thức của mô hình 5 yếu tố (Big Five Model). Trong đó các yếu tố lớn hình thành mô hình 5 đặc điểm tính cách gồm: tâm lý bất ổn (neuroticism), hướng ngoại (extraversion), sự dễ chịu (agreeableness), sự tận tâm (conscientiousness) và sẵn sàng trải nghiệm (openness to experience).

\section{Hướng ngọ̣i (extraversion)}

Costa và McCrae (1992) cho rằng cá nhân có tính hướng ngoại thường vui vẻ, lạc quan và có khả năng kết bạn với những người khác. Ngoài ra, họ còn có xu hướng hoà đồng hơn, chủ động, lạc quan, vui vẻ (McCrae \& Sutin, 2009). Theo Weller và Tikir (2011) cá nhân hướng ngoại thể hiện sự lạc quan, quyết đoán và tràn đầy năng lượng.

\section{Tâm lý bất ổn (neuroticism)}

Tâm lý bất ổn là sự đối nghịch của ổn định cảm xúc, những đặc điểm này chứa các khía cạnh của những cảm xúc tiêu cực và yếu đuối như lo lắng, dễ bị tổn thương, nhút nhát và trầm cảm (Costa \& McCrae, 1992). Ngoài ra, các cá nhân bất ổn tâm lý thường thiếu tự tin và sự tự kiểm soát cần thiết cho tinh thần trong kinh doanh (Chen, Greene, \& Crick, 1998). Nghiên cứu của Hoch và Loewenstein (1991) cũng cho thấy những cá nhân ổn định về mặt cảm xúc tự tin hơn, có trách nhiệm hơn và có khả năng quản lý mọi việc tốt hơn theo kế hoạch của họ.

\section{Sụ dễ chịu (agreeableness)}

Costa và McCrae (1992) cho rằng sự dễ chịu mô tả các hành vi tin tưởng, tha thứ, tốt bụng và đồng cảm. Những cá nhân này có xu hướng hợp tác hơn, có mối quan hệ xã hội tốt hơn những người có ít sự dễ chịu, họ có thể dễ nghi ngờ, tự cho mình là trung tâm và vô tình. Ngoài ra, họ còn rất thân thiện, ấm áp và tương tác tốt với xã hội (McCrae \& Costa, 1997). Cá nhân họ cũng rất dễ tha thứ, dịu dàng, tốt bụng và hoà đồng với đồng nghiệp (Martins, 2002).

\section{Sự tận tâm (conscientiousness)}

Sự tận tâm mô tả sự đáng tin cậy, cần cù và sự kiên trì của một cá nhân (Martins, 2002). Theo Gunkel, Sclaegel, Langella, và Peluchette (2010) những cá nhân có sự tận tâm, họ thường có năng lực làm việc cao, có sự tự kỷ luật và tự chủ trong việc ra quyết định. Cá nhân có điểm cao ở mặt này thường có mong muốn hoàn thành công việc được giao một cách tốt nhất và thường đặt ra mục tiêu để đạt được những thành tựu trong công việc. Những cá nhân có điểm thấp ở mặt tính này thường rất dễ dãi, không có mục tiêu nhất định, thường không đáng tin cậy (Hai, 2015)

\section{Sẵn sàng trải nghiệm (openness to experience)}

Sẵn sàng trải nghiệm mô tả sự cởi mở và niềm đam mê đối với những ý tưởng mới (McCrae \& Costa, 1997). Còn là tính cách của sự thích mới lạ, tìm kiếm kinh nghiệm mới và những cá nhân sẵn sàng trải nghiệm cũng thích sự sáng tạo và đổi mới (Zhao \& Seibert, 2006). Ngoài ra, các đặc điểm của mặt tính cách này là: thích phiêu lưu trải nghiệm, trân trọng nghệ thuật, hiếu kỳ, có những ý tưởng độc đáo, có óc thẩm mỹ. Tính cách sẵn sàng trải nghiệm thể hiện mức độ hiếu kỳ, tính sáng tạo và thích trải nghiệm. Những cá nhân có điểm cao ở mặt này thường rất khó dự đoán và không tập trung (Hai, 2015).

\section{Thái độ đối với rủi ro tài chính}

Theo Xiao và cộng sự (2010) thì hành vi của con người rất phức tạp, và các khía cạnh hành 
vi tài chính thậm chí còn phức tạp hơn. Hành vi tài chính của một người phụ thuộc vào các yếu tố môi trường và các yếu tố cá nhân. Các yếu tố môi trường bao gồm lạm phát, lãi suất, dịch vụ tài chính, và sự vận hành của môi trường hiện tại. Cá nhân không kiểm soát trực tiếp các yếu tố môi trường, mà chỉ có thể bảo vệ mình bằng cách thích ứng theo các yếu tố đó. Các yếu tố cá nhân bao gồm thái độ cá nhân đối với rủi ro tài chính, thái độ tổng thể và khả năng tài chính cá nhân, bao gồm cả tâm lý cá nhân. Những yếu tố khác nhau giữa người này sang người khác, và trong hầu hết các trường hợp, nhà đầu tư có thể kiểm soát các yếu tố này. Những yếu tố cá nhân ảnh hưởng đến cảm xúc của họ và từ đó có tác động đến việc ra quyết định tài chính (Hira, 2012).

Hiện nay đã có một sự tập trung vào vai trò của các yếu tố nhân khẩu học, kinh tế xã hội và tâm lý về thái độ đối với rủi ro tài chính của các cá nhân. Theo Sages và Grable (2010) chấp nhận rủi ro tài chính hay thái độ đối với rủi ro tài chính được định nghĩa là số tiền cao nhất của sự không chắc chắn mà nhà đầu tư sẵn sàng chấp nhận khi đưa ra quyết định tài chính.

\section{Ý định đầu tư tài chính}

Theo nghiên cứu của Joo và Grable (2004) chỉ ra rằng sự thỏa mãn tài chính được tác động từ yếu tố rủi ro tài chính trong hành vi của các cá nhân. Theo Garman và Forgue (1997) thì các hành vi tài chính của một cá nhân có thể được đánh giá dựa trên cơ sở các kỹ thuật quản lý tài chính. Quản lý tài chính bao gồm kế hoạch về việc hoàn thành các mục tiêu ngắn hạn và dài hạn như nhà ở, ô tô và nhu cầu đầu tư cho tương lai (Britt et al., 2012). Các ý định đầu tư tài chính cá nhân có thể được phân loại thành hai loại là ý định đầu tư tài chính dài hạn và ngắn hạn (Nga \& Yien, 2013). Ý định đầu tư tài chính dài hạn của các cá nhân liên quan đến các sản phẩm có kỳ hạn dài để đáp ứng nhu cầu tài chính trong dài hạn. Trong khi những ý định đầu tư tài chính ngắn hạn của các cá nhân liên quan đến việc đáp ứng nhu cầu tài chính trong tương lai gần.

\section{Thế hệ Y}

Theo Miller và Washington (2009) thế hệ Y hay có tên gọi khác là Millennials là những người sinh từ năm 1977 đến 2000. Mothersbaugh và Hawkins (2016) nêu lên các yếu tố làm cho thế hệ Y có nét riêng so với các thế hệ khác bao gồm: sử dụng công nghệ, thích âm nhạc và văn hoá pop, có tính khoan dung, thông minh và yếu thích thời trang.

\subsection{Các giả thuyết}

\section{Hướng ngoại và Thái độ đối với rủi ro tài chính}

Pan và Statman (2013) cho rằng người hướng ngoại có khả năng chịu rủi ro cao hơn những người ít hướng ngoại. Trong khi đó, Durand, Newby, và Sanghani (2008) xem xét mối quan hệ giữa các đặc điểm tính cách với danh mục đầu tư, họ thấy rằng những người hướng ngoại đầu tư nhiều vào cổ phiếu so với những người ít hướng ngoại. Oehler, Wendt, Wedlich, và Horn (2016) người hướng ngoại sẵn sàng trả giá cao hơn cho đầu tư tài chính. Brown và Taylor (2014) cho rằng người hướng ngoại chấp nhận mắc nợ và có thể chịu được nhiều rủi ro hơn so với người ít hướng ngoại. Các điều này cũng là dấu hiệu cho thấy người hướng ngoại ít có thái độ đối với rủi ro tài chính. Vì vậy, giả thuyết $\mathrm{H} 1$ có thể được phát biểu như sau:

\section{H1: Huớng ngoại có tác động nghịch biến đến thái độ đối với rủi ro tài chinh}

\section{Tâm lý bất ổn và Thái độ với rủi ro tài chính}

Tâm lý bất ổn là đối nghịch với sự ổn định cảm xúc. Đặc điểm của khía cạnh này chứa những cảm xúc tiêu cực và yếu đuối như lo lắng, dể bị tổn thương, nhút nhát và trầm cảm (Costa \& McCrae, 1992). Cá nhân có tâm lý bất ổn thường có góc nhìn bi quan, điều này có thể ảnh hưởng đến sự sẵn lòng để chấp nhận rủi ro trong đầu tư, do đó trong việc đầu tư sẽ phù hợp hơn 
với những cá nhân ổn định về tâm lý (Chitra \& Sreedevi, 2011). Vì vậy, giả thuyết H2 có thể được phát biểu như sau:

\section{H2: Tâm lý bất ổn có tác động đồng biến đến thái độ đối với rủi ro tài chính}

\section{Sự dễ chịu và Thái độ rủi ro tài chính}

Sự dễ chịu bao gồm các khía cạnh ưa thích xã hội, nó bao gồm hành vi tin tưởng, tha thứ và chăm sóc (McCrae \& Costa, 1997). Cá nhân có tính dễ chịu thường tránh cãi nhau, bất đồng và bạo lực và do những sự tiêu cực này mâu thuẫn với tính cánh dễ chịu của họ. Do đó, các nhà nghiên cứu đã tìm ra mối quan hệ phủ định giữa sự dễ chịu và thái độ rủi ro tài chính (Arthur \& Graziano, 1996). Vì vậy, giả thuyết H3 có thể được phát biểu như sau:

\section{H3: Sự dễ chịu có tác động nghịch biến đến thái độ đối với rủi ro tài chính}

\section{Sự tận tâm và Thái độ rủi ro tài chính}

Sự tận tâm thể hiện sự tiêu cực về sự ngẫu nhiên (Sadi, Asl, Rostami, Gholipour, \& Gholipour, 2011). Điều này chỉ ra rằng, cá nhân đầu tư ít phụ thuộc vào may mắn và mê tín mà họ thường cận thẩn, tỉ mỉ trong việc ra quyết định đầu tư và cụ thể cho loại hình đầu tư của họ, nên họ sẵn sàng chấp nhập rủi ro khi đã đầu tư. Cùng kết quả, nghiên cứu của Mayfield, Perdue, và Wooten (2008) cho rằng những cá nhân có sự tận tâm sẽ chấp nhận rủi ro cao hơn những cá nhân không có sự tận tâm. Vì vậy, giả thuyết H4 có thể được phát biểu như sau:

\section{H4: Sụ tận tâm có tác động nghịch biến đến thái độ đối với rủi ro tài chính}

\section{Sẵn sàng trải nghiệm và Thái độ rủi ro tài chính}

Tính cách của người luôn sẵn sàng trải nghiệm là người thích sự mới lạ và tìm kiếm những trải nghiệm mới. Sự sẵn sàng trải nghiệm đề cập đến sự sáng tạo, trí tưởng tượng và đổi mới (Zhao \& Seibert, 2006). Sự sẵn sàng trải nghiệm được coi là sự kích thích cho nhận thức chấp nhận rủi ro (McCrae \& Costa, 1997). Vì vậy, giả thuyết H5 có thể được phát biểu như sau:

H5: Sã̃n sàng trải nghiệm có tác động nghịch biến đến thái độ đối với rủi ro tài chính

\section{Thái độ rủi ro tài chính và Ý định đầu tư}

Thái độ rủi ro tài chính được coi là một yếu tố quan trọng liên quan đến hành vi đầu tư (Kiev, 2003). Keller và Siegrist (2006) cho rằng rủi ro tài chính, mức thu nhập và khoản đầu tư tác động đáng kể ý định đầu tư.

Theo Lim, Soutar, và Lee (2013) cho rằng thái độ rủi ro tài chính và ý định đầu tư tài chính có mối quan hệ tiêu cực. Cùng kết quả, theo Mayfield và cộng sự (2008) thì thái độ rủi ro tài chính càng lớn, cá nhân đầu tư tài chính càng ít đầu tư dài hạn hoặc ngắn hạn. Vì vậy, giả thuyết H6, H7 có thể được phát biểu như sau:

H6: Thái độ rủi ro tài chính có tác động nghịch biến đến ý định đầu tu tài chính ngắn hạn

H7: Thái độ rủi ro tài chính có tác động nghịch biến đến ý định đầu tư tài chính dài hạn

\subsection{Mô hình nghiên cúu}

Với bảy giả thuyết được hình thành và biện luận ở trên, mô hình nghiên cứu được xây dựng trong Hình 1. Trong đó, các yếu tố hướng ngoại, tâm lý bất ổn, sự dễ chịu, sự tận tâm và sẵn sàng trải nghiệm tác động trực tiếp lên thái độ đối với rủi ro tài chính. Từ đó, yếu tố thái độ đối với rủi ro tài chính sẽ có ảnh hưởng đến ý định đầu tư tài chính, cụ thể là ý định đầu tư ngắn hạn và ý định đầu tư dài hạn. 


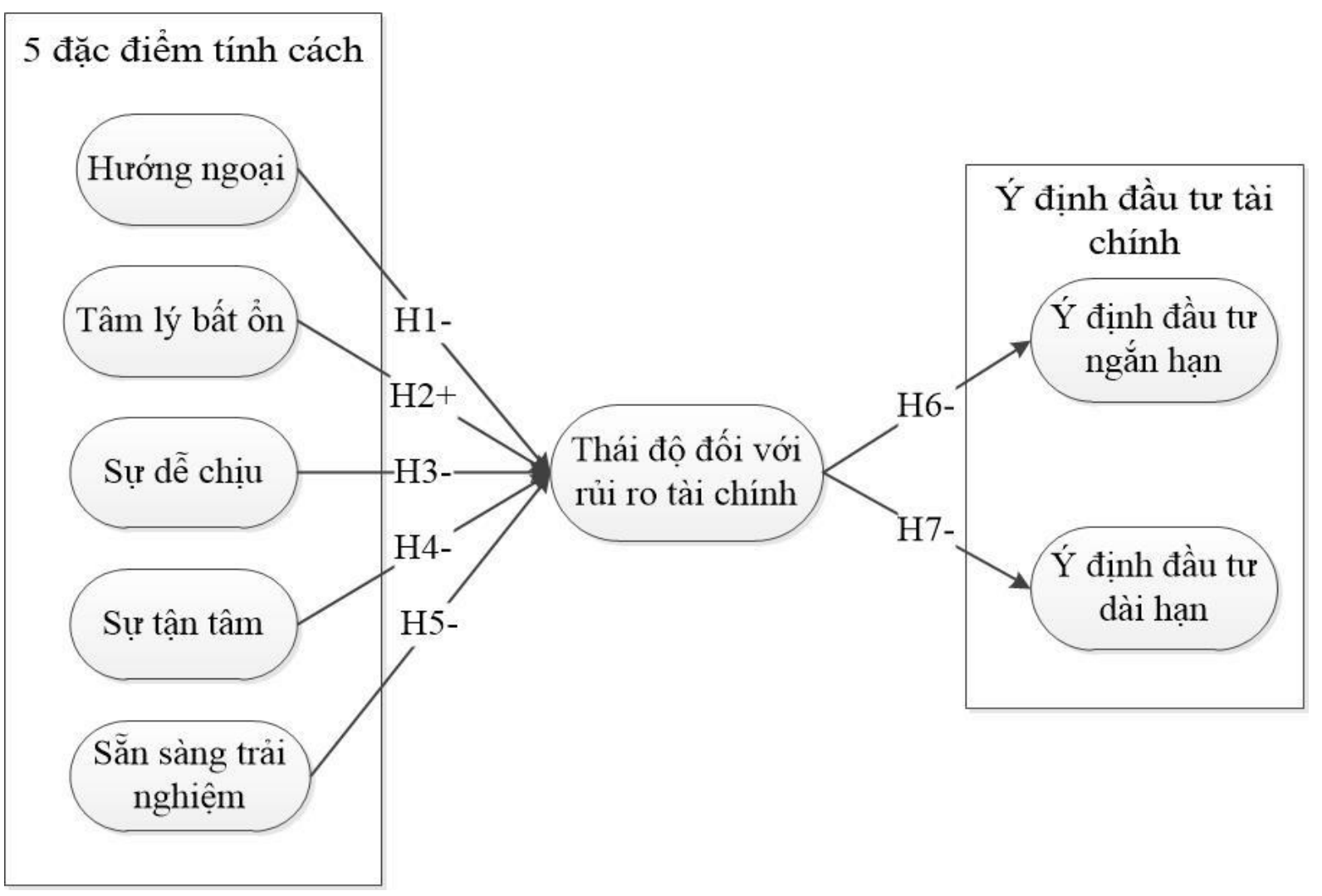

Hình 1. Mô hình nghiên cứu đề xuất

\section{Phương pháp nghiên cứu}

Mô hình và các giả thuyết được kiểm định dựa trên bộ dữ liệu có kích thước mẫu là 277. Mẫu được thu thập qua một cuộc khảo sát theo phương pháp lấy mẫu thuận tiện tại Tp. Hồ Chí Minh. Đối tượng khảo sát là những cá nhân Việt Nam có độ tuổi từ 20 đến 43 tuổi. Họ là những người đã biết đến/ đã tìm hiểu về đầu tư tài chính (được nhận dạng thông qua câu hỏi gạn lọc). Phương pháp tiếp cận là phỏng vấn trực tiếp tại nơi làm việc, học tập, tại nhà hoặc nơi thuận tiện khác.

Tất cả nội dung của thang đo được kế thừa từ nghiên cứu của Nadan và Saurabh (2016), có hiệu chỉnh thông qua bước phỏng vấn sơ bộ và không có sự thay đổi biến so với thang đo kế thừa (xem Bảng 2). Cụ thể, thang đo Hướng ngoại gồm 4 biến quan sát, Tâm lý bất ổn gồm 5 biến quan sát, Sự dễ chịu gồm 4 biến quan sát, Sự tận tâm gồm 4 biến quan sát, Sẵn sàng trải nghiệm gồm 4 biến quan sát, Ý định đầu tư tài chính ngắn hạn gồm 4 biến quan sát, Ý định đầu tư tài chính dài hạn gồm 4 biến quan sát, Thái độ đối với rủi ro tài chính gồm 4 biến quan sát. Các thang đo có dạng Likert 5 điểm.

\section{Kết quả nghiên cứu}

\subsection{Mô tả mẫu}

Như trình bày ở Bảng 1 cho thấy về giới tính, 165 nam $(59,6 \%)$ và 112 nữ $(40,4 \%) ; 58$ cá nhân đầu tư tài chính thuộc độ tuổi 20 - 22 chiếm $(21 \%), 122$ cá nhân đầu tư tài chính thuộc độ tuổi 23 - 30 chiếm (44\%), 97 cá nhân đầu tư tài chính thuộc độ tuổi 31 - 43 chiếm (35\%). Phân bố thu nhập cụ thể là dưới 4 trđ/th (14,1\%), 4 - dưới 9 trđ/th (20,2\%), 9 - dưới 15 trđ/th $(38,3 \%)$, 15 trđđ/th - dưới 25 trđđ/th $(19,8 \%)$ và trên 25 trđ/th $(7,6 \%)$. Qua đó cho thấy mẫu khảo sát là đủ đa dạng cho các phân tích thống kê và phản ánh nhóm người tiềm năng trong việc đầu tư tài chính. 


\section{Bảng 1}

Mô tả mẫu (n=277)

\begin{tabular}{|c|c|c|c|}
\hline \multicolumn{4}{|c|}{ Giới tính } \\
\hline Giới tính & Tần số & Tỷ lệ \% & Tỷ lệ \% tích lũy \\
\hline Nam & 165 & 59,6 & 59,6 \\
\hline Nữ & 112 & 40,4 & 100 \\
\hline Tổng & 277 & 100 & \\
\hline \multicolumn{4}{|c|}{ Tuổi } \\
\hline Độ tuổi & Tần số & Tỷ lệ \% & Tỷ lệ \% tích lũy \\
\hline 20-22 tuổi & 58 & 21,0 & 21,0 \\
\hline 23-30 tuổi & 122 & 44,0 & 65,0 \\
\hline 31-43 tuổi & 97 & 35,0 & 100,0 \\
\hline Tổng & 277 & 100 & \\
\hline \multicolumn{4}{|c|}{ Thu nhập } \\
\hline Thu nhập & Tần số & Tỷ lệ \% & Tỷ lệ \% tích lũy \\
\hline Dưới 4 triệu VNĐ & 39 & 14,1 & 14,1 \\
\hline Từ 4 triệu đến dưới 9 triệu VNĐ & 56 & 20,2 & 34,3 \\
\hline Từ 9 triệu đến dưới 15 triệu VNĐ & 106 & 38,3 & 72,6 \\
\hline Từ 15 triệu đến dưới 25 triệu VNĐ & 55 & 19,8 & 92,4 \\
\hline Từ 25 triệu VNĐ trở lên & 21 & 7,6 & 100,0 \\
\hline Tổng & 277 & 100 & \\
\hline
\end{tabular}

Nguồn: Kết quả phân tích dữ liệu của nhóm nghiên cứu

\section{2. Đánh giá và gạn lọc thang đo}

Các thang đo được đánh giá sơ bộ bằng phân tích độ tin cậy và phân tích nhân tố khám phá (EFA).

Kết quả phân tích độ tin cậy cho thấy cả 8 thang đo đều có hệ số Cronbach's Alpha lớn hơn 0,6 và các biến quan sát của các thang đo này đều có tương quan biến_tổng lớn hơn 0,3 , do đó có thể kết luận các thang đo này đều đạt độ tin cậy.

Kết quả phân tích nhân tố khám phá (EFA) cho thấy có 8 nhân tố được trích ra với 30 biến quan sát (loại 3 biến quan sát do có hệ số tải nhân tố nhỏ hơn 0,5 là: 1 biến thuộc thang đo tâm lý bất ổn, 1 biến thuộc thang đo sự tận tâm, 1 biến thuộc thang đo ý định đầu tư dài hạn và tổng phương sai trích là $57,998 \%>50 \%$, hệ số $\mathrm{KMO}$ là $0,868>0,5$, kiểm định Bartllet có $\mathrm{p}<$ 0,05 , vì vậy phân tích nhân tố được xem là thích hợp, 8 thang đo với 30 biến còn lại được đưa vào kiểm định chính thức bằng phân tích nhân tố khẳng định (CFA). 


\section{Bảng 2}

Kết quả đánh giá thang đo

\begin{tabular}{|c|c|}
\hline Thang đó và biến quan sát & $\begin{array}{l}\text { Hệ số tải } \\
\text { chuẩn hoá }\end{array}$ \\
\hline \multicolumn{2}{|l|}{ Hướng ngoại: Cronbach's Alpha $=0,811 ; \mathrm{CR}=0,816 ; \mathrm{AVE}=0,526$} \\
\hline Tôi rất thích nói chuyện với người khác & 0,784 \\
\hline Tôi thường cảm thấy mình tràn đầy năng lượng & 0,685 \\
\hline Tôi thường vui vẻ, tinh thần hứng khởi & 0,677 \\
\hline Tôi là một người rất tích cực & 0,750 \\
\hline \multicolumn{2}{|l|}{ Tâm lý bất ổn: Cronbach's Alpha = 0,856; CR = 0,863; AVE =0,612 } \\
\hline Tôi thưòng cảm thấy thua kém nguời khác & * \\
\hline Khi gặp nhiều căng thẳng, tôi khó tập trung tư tưởng & 0,753 \\
\hline Tôi thường cảm thấy căng thẳng và bồn chồn & 0,792 \\
\hline Đôi khi tôi cảm thấy mình hoàn toàn vô giá trị & 0,802 \\
\hline Thông thường khi gặp sai sót, tôi chán nản và muốn bỏ cuộc & 0,781 \\
\hline \multicolumn{2}{|l|}{ Sự dễ chịu: Cronbach's Alpha $=0,874 ; C R=0,875 ; A V E=0,636$} \\
\hline Tôi thường tranh cãi với gia đình và bạn bè & 0,812 \\
\hline Một số người cho rằng tôi ích kỷ và tự cao tự đại & 0,797 \\
\hline Một số người cho rằng tôi lạnh lùng và tính toán & 0,766 \\
\hline Tôi thường cố gắng thể hiện sự chu đáo và ân cần & 0,814 \\
\hline \multicolumn{2}{|l|}{ Sụ̣ tận tâm: Cronbach's Alpha $=0,774 ; C R=0,792 ; A V E=0,559$} \\
\hline Tôi giữ đồ đạc của mình gọn gàng và sạch sẽ & 0,723 \\
\hline $\begin{array}{l}\text { Tôi giỏi việc điều tiết nhịp sống của mình để có thể thực hiện công việc đúng thời } \\
\text { hạn }\end{array}$ & 0,779 \\
\hline Tôi dành nhiều thời gian chuẩn bị trước khi giải quyết công việc & 0,740 \\
\hline Tôi gặp khó khăn khi tụ đura bản thân vào một khuôn khổ kỷ luật & $*$ \\
\hline \multicolumn{2}{|l|}{ Sã̃n sàng trải nghiệm: Cronbach's Alpha $=0,806 ; C R=0,806 ; A V E=0,511$} \\
\hline Tôi bị hấp dẫn bởi những nét nghệ thuật và thiên nhiên & 0,749 \\
\hline Tôi thường thử thức ăn mới hoặc các món nước ngoài & 0,687 \\
\hline Tôi ít quan tâm về bản chất của vũ trụ hoặc về thân phận con người & 0,689 \\
\hline Tôi thường thích thú với các lý thuyết hay các ý tưởng trừu tượng & 0,731 \\
\hline \multicolumn{2}{|l|}{$\begin{array}{l}\text { Ý định đầu tư tài chính ngắn hạn: Cronbach's Alpha =0,830; CR =0,831; } \\
\qquad \mathrm{AVE}=0,553\end{array}$} \\
\hline Đặt ít nhất một nửa số tiền đầu tư của mình vào thị trường chứng khoán & 0,761 \\
\hline Tham gia vào các hoạt động quản lý tập danh mục đầu tư ít nhất hai lần mỗi tuần & 0,815 \\
\hline Thực hiện đầu tư nghiên cứu của riêng tôi thay vì sử dụng dịch vụ tư vấn bên ngoài & 0,653 \\
\hline
\end{tabular}




\begin{tabular}{|c|c|}
\hline So sánh hiệu suất danh mục đầu tư của tôi với các nhà quản lý chuyên nghiệp & 0,736 \\
\hline \multicolumn{2}{|l|}{$\begin{array}{l}\text { Ý định đầu tư tài chính dài hạn: Cronbach's Alpha =0,791; CR =0,771; } \\
\qquad \mathrm{AVE}=\mathbf{0 , 5 3 0}\end{array}$} \\
\hline Để tiết kiệm ít nhất 10\% tổng thu nhập cho mục đích đầu tư/ tiết kiệm/ nghỉ hưu & 0,768 \\
\hline $\begin{array}{l}\text { Lập một danh mục đầu tu vào nhiều loại tài sản (cổ phiếu, trái phiếu, tiền mặt, bất } \\
\text { động sản, v.v) }\end{array}$ & $*$ \\
\hline Tìm hiểu về các lựa chọn đầu tư & 0,668 \\
\hline Đầu tư một số tiền vào các tài sản dài hạn & 0,745 \\
\hline \multicolumn{2}{|l|}{$\begin{array}{l}\text { Thái độ rủi ro tài chính: Cronbach's Alpha }=0,811 ; \mathrm{CR}=0,812 ; \\
\qquad \mathrm{AVE}=\mathbf{0 , 5 2 0}\end{array}$} \\
\hline Tôi không sẵn sàng chấp nhận rủi ro khi lựa chọn một cổ phiếu hoặc đầu tư & 0,670 \\
\hline $\begin{array}{l}\text { Tôi muốn có một mức độ rủi ro thấp với một hiệu suất ổn định hơn là một khoản } \\
\text { đầu tư có mức rủi ro cao dù lợi nhuận cao hơn }\end{array}$ & 0,764 \\
\hline $\begin{array}{l}\text { Tôi thích giữ chiến lược đầu tư rõ ràng; thay vì mạo hiểm thử một chiến lược đầu tư } \\
\text { mới có vấn đề chưa rõ ràng, ngay cả khi chiến lược đầu tư mới có lợi nhuận rất lớn }\end{array}$ & 0,673 \\
\hline Tôi xem rủi ro trong đầu tư là một tình huống cần phải tránh bằng mọi giá & 0,771 \\
\hline
\end{tabular}

Ghi chú: * Loại qua EFA

Nguồn: Kết quả phân tích dữ liệu của nhóm nghiên cứu

Kết quả phân tích nhân tố khẳng định $(\mathrm{CFA})$ có Chi-square $=451.881 ; \mathrm{df}=377 ; \mathrm{p}=$ 0,005 nhỏ hơn 0,05; Chi-square/df $=1,199$ nhỏ hơn 3; GFI = 0,900; CFI = 0,978; TLI = 0,975 đều lớn hơn hoặc bằng 0,9 và $\mathrm{RMSEA}=0,027$ nhỏ hơn 0,08 , vì vậy có thể kết luận mô hình đo lường này phù hợp với dữ liệu thực tế.

Như thể hiện trên Bảng 2, hệ số tải chuẩn hoá của các biến dao động từ 0,653 đến 0,815 đều lớn hơn 0,5 đồng thời phương sai trích của các thang đo AVE dao động từ 0,511 đến 0,636 đều lớn hơn 0,5 nên các thang đo đạt giá trị hội tụ. Độ tin cậy tổng hợp (CR) co giá trị từ 0,771 đến 0,875 đều lớn hơn 0,7 nên các thang đo đạt độ tin cậy. Tương quan giữa các khái niệm dao động từ 0,520 tới 0,636 , thấp xa đáng kể với $1(\mathrm{p}=0,05)$ nên các thang đo đạt độ giá trị phân biệt.

\subsection{Kiểm định mô hình cấu trúc tuyến tính}

Kết quả kiểm định mô hình cấu trúc tuyến tính cho thấy mô hình này có giá trị Chisquare $=562.968 ; \mathrm{df}=388 ; \mathrm{p}=0,000$ nhỏ hơn 0,05; Chi-square/df $=1,451 ; \mathrm{CFI}=0,948 ; \mathrm{TLI}=$ 0,942 ; GFI $=0,874$ nhỏ hơn 0,9 , tuy nhiên Nguyen và Nguyen (2011) thì một mô hình có Chisquare/df nhỏ hơn 2 , TLI, CFI lớn hơn 0,9 và RMSEA $=0,04$ nhỏ hơn 0,08 thì có thể kết luận là mô hình này phù hợp tốt với dữ liệu thu thập được từ thực tiễn và $33 \%$ phương sai của yếu tố ý định đầu tư ngắn hạn, $39 \%$ phương sai của yếu tố ý định đầu tư dài hạn được giải thích bởi các yếu tố có trong mô hình nghiên cứu.

Kết quả ước lượng (Bảng 3) cho thấy các mối quan hệ kiểm định đều có ý nghĩa về mặt thống kê $(\mathrm{p}<0,05)$, và hệ số chuẩn hoá của $\mathrm{H} 2, \mathrm{H} 3, \mathrm{H} 4, \mathrm{H} 5, \mathrm{H} 6, \mathrm{H} 7$ cùng dấu với giả thuyết đề ra nên được ủng hộ.

Giả thuyết $\mathrm{H} 1$ tuy có $\mathrm{p}<0,05$ nhưng dấu của hệ số hồi quy chuẩn hóa ngược với dấu của giả thuyết $\mathrm{H} 1$ đề xuất nên giả thuyết này không được ủng hộ. 


\section{Bảng 3}

Kết quả kiểm định mô hình cấu trúc tuyến tính

\begin{tabular}{|l|c|c|c|}
\hline \multicolumn{1}{|c|}{ Mối quan hệ } & $\begin{array}{c}\text { Hệ số } \\
\text { chuấn hoá }\end{array}$ & p & $\begin{array}{c}\text { Kiểm định } \\
\text { giả thuyết }\end{array}$ \\
\hline Hướng ngoại -> Thái độ đối với rủi ro tài chính & 0,188 & 0,018 & Bác bỏ H1 \\
\hline Tâm lý bất ổn -> Thái độ đối với rủi ro tài chính & 0,251 & 0,004 & Ủng hộ H2 \\
\hline Sự dễ chịu -> Thái độ đối với rủi ro tài chính & $-0,212$ & 0,003 & Ủng hộ H3 \\
\hline Sự tận tâm -> Thái độ đối với rủi ro tài chính & $-0,251$ & 0,003 & Ủng hộ H4 \\
\hline Sẵn sàng trải nghiệm -> Thái độ đối với rủi ro tài chính & $-0,272$ & 0,002 & Ủng hộ H5 \\
\hline Thái độ đối với rủi ro tài chính -> Ý định đầu tư ngắn hạn & $-0,577$ & 0,002 & Ủng hộ H6 \\
\hline Thái độ đối với rủi ro tài chính -> Ý định đầu tư dài hạn & $-0,623$ & 0,002 & Ưng hộ H7 \\
\hline
\end{tabular}

Nguồn: Kết quả phân tích dữ liệu của nhóm nghiên cứu

\section{Thảo luận kết quả}

\section{Mối quan hệ giữa 5 đặc điểm tính cách và thái độ đối với rủi ro tài chính}

Kết quả kiểm định mô hình cấu trúc tuyến tính cho thấy mối quan hệ của tính hướng ngoại và thái độ rủi ro tài chính có hệ số $\beta=0,188$ bị bác bỏ, do đó tính cách hướng ngoại của các nhà đầu tư cá nhân thế hệ Y không có mối quan hệ tác động đến thái độ rủi ro tài chính. Như vậy các nhà môi giới hay nhà phân tích về đầu tư cá nhân không thể dựa trên tính cách hướng ngoại để dự báo hành vi đầu tư của nhà đầu tư cá nhân thế hệ Y tại Việt Nam.

Kết quả kiểm định mô hình cấu trúc tuyến tính cho thấy mối quan hệ của tâm lý bất ổn và thái độ rủi ro tài chính có hệ số $\beta=0,251$, điều này cho thấy tâm lý bất ổn có mối quan hệ đồng biến với thái độ rủi ro tài chính. Nghĩa là nhà đầu tư cá nhân có tâm lý càng không ổn định thì sẽ có thái độ đối với rủi ro tài chính càng cao. Như vậy, các nhà môi giới hay nhà phân tích về đầu tư cá nhân muốn thu hút nhà đầu tư cá nhân có tâm lý bất ổn đầu tư tài chính thì cần phải tư vấn kỹ, đưa ra các phương án khác nhau hay các công cụ phòng ngừa rủi ro, cũng như thường xuyên theo dõi và tư vấn kịp thời trước những biến động của thị trường, ... nhằm giúp đối tượng khách hàng này yên tâm hơn.

Kết quả kiểm định mô hình cấu trúc tuyến tính cho thấy mối quan hệ của sự dễ chịu và thái độ rủi ro tài chính có hệ số $\beta=-0,212$; sẵn sàng trải nghiệm và thái độ rủi ro tài chính với $\beta$ $=-0,272$; sự tận tâm và thái độ rủi ro tài chính có hệ số $\beta=-0,251$, điều này cho thấy sự dễ chịu, sẵn sàng trải nghiệm, sự tận tâm, đều có mối quan hệ nghịch biến với thái độ rủi ro tài chính. Nghĩa là nhà đầu tư cá nhân có các tính cách sự dễ chịu, sằn sàng trải nghiệm, sự tận tâm càng cao thì sẽ có thái độ đối với rủi ro tài chính càng thấp. Dựa vào hệ số $\beta$ cho thấy nhà đầu tư cá nhân có tính cách sẵn sàng trải nghiệm có thái độ với rủi ro tài chính là thấp nhất, tiếp đó là sự tận tâm và sự dễ chịu. Như vậy các nhà môi giới hay nhà phân tích về đầu tư cá nhân có thể dễ thu hút đầu tư tài chính từ những nhà đầu tư cá nhân có ba tính cách này theo thứ tự ưu tiên là sẵn sàng trải nghiệm, sự tận tâm, sự dễ chịu.

\section{Mối quan hệ giữa thái độ đối với rủi ro tài chính và ý định đầu tư tài chính}

Kết quả kiểm định mô hình cấu trúc tuyến tính cho thấy mối quan hệ của thái độ rủi ro tài chính và ý định đầu tư tài chính ngắn hạn có hệ số $\beta=-0,577$; thái độ rủi ro tài chính và ý định đầu tư tài chính dài hạn có hệ số $\beta=-0,623$, điều này cho thấy thái độ đối với rủi ro tài chính đều có tác động nghịch biến lên ý định đầu tư tài chính bao gồm cả ngắn hạn và dài hạn. Với kết quả 
này, cho thấy nhà đầu tư cá nhân thế hệ Y tại Việt Nam có thái độ đối với rủi ro tài chính càng cao thì càng ít có ý định đầu tư tài chính ngắn hạn hơn so với dài hạn. Nghĩa là, họ sẽ thiên về hành vi đầu tư tài chính dài hạn hơn là quá trình đầu tư tài chính ngắn hạn. Nên các nhà môi giới hay nhà phân tích về đầu tư cá nhân tập trung tư vấn và thu hút những nhà đầu tư cá nhân này bằng các hình thức đầu tư dài hạn như đầu tư bất động sản, mua trái phiếu chính phủ, đầu tư chứng khoán dài hạn etc.

Sự hiểu biết về tính cách của các nhà đầu tư tài chính về thái độ rủi ro tài chính và thái độ rủi ro tài chính tác động lên đầu tư dài hạn hay ngắn hạn sẽ giúp cho các nhà quản lý hay nhà môi giới cố vấn về tài chính được hiểu quả hơn hoặc cố vấn về cách thức và hình thức đầu tư cho nhà đầu tư tài chính thế hệ Y ở Việt Nam được tốt hơn. Ngoài ra, nhà quản lý, nhà môi giới hay nhà phân tích về đầu tư tài chính có thể xác định được nhu cầu của nhà đầu tư cá nhân tiềm năng của mình, để từ đó họ thoả mãn nhu cầu nhà đầu tư cá nhân thông qua chiến lược tiếp thị hoặc điều chỉnh các sản phẩm và dịch vụ phù hợp hơn.

Để thu hút các nhà đầu tư tài chính cá nhân thế hệ Y thì các nhà tư vấn đầu tư tài chính, các công ty đầu tư tài chính cần hiểu rõ các đặc điểm tính cách của cá nhà đầu tư thế hệ này, để từ đó có chiến lược đào tạo hay tuyển dụng nhân sự nhằm nâng cao năng lực của đội ngũ tư vấn đầu tư tài chính.

\section{Kết luận}

Nghiên cứu này tập trung vào việc khám phá các đặc điểm tính cách tác động lên thái độ đối với rủi ro tài chính và thái độ đối với rủi ro tài chính tác động lên ý định đầu tư tài chính cá nhân trong ngắn hạn và dài hạn. Kết quả cho thấy yếu tố tâm lý bất ổn có tác động đồng biến với thái độ đối với rủi ro tài chính, các yếu tố sự dễ chịu, sự tân tâm và sẵn sàng trải nghiệm có tác động nghịch biến với thái độ đối với rủi ro tài chính, còn mối quan hệ giữa yếu tố hướng ngoại và thái độ đối với rủi ro tài chính không được ủng hộ; đồng thời, thái độ đối với rủi ro tài chính có tác động nghịch biến lên ý định đầu tư tài chính dài hạn và ý định đầu tư tài chính ngắn hạn. Kết quả này giúp các nhà môi giới, các công ty tài chính có thể sử dụng mô hình nghiên cứu này trong việc xây dựng các chiến lược kinh doanh và các chiến lược cung cấp dịch vụ phù hợp với từng đối tượng nhà đầu tư dựa trên đặc điểm tính cách cũng như thái độ đối với rủi ro tài chính của họ.

Như những nghiên cứu khác, bài viết cũng còn một số hạn chế. Bên cạnh việc không tìm thấy sự khác biệt trong kết quả giữa các nhóm thu nhập, có thể có sự khác biệt liên quan đến yếu tố khác như nhóm tuổi, hoặc trình độ học vấn. Thêm vào đó, các nghiên cứu tiếp theo củng có thể mở rộng các đặc điểm tính cách tác động lên thái độ rủi ro tài chính cá nhân tại Việt Nam.

\section{Tài liệu tham khảo}

Arthur, W., \& Graziano, W. G. (1996). The five factor model, conscientiousness, and driving accident involvement. Journal of Personality, 64(3), 593-618.

Britt, S. L., Fernatt, F., Nelson, J. S., Yook, M., Blue, J. M., \& Canale, A. (2012). The efficacy of financial counseling for college students. Cosumer Interests Annual, 58, 1-8.

Brown, S., \& Taylor, K. (2014). Household finances and the "big five'personality traits". Journal of Economic Psychology, 45, 197-212.

Chen, C. C., Greene, P. G., \& Crick, A. (1998). Does entrepreneurial self-efficacy distinguish entrepreneurs from managers? Journal of Business Venturing, 13(4), 295-316. 
Chitra, K., \& Sreedevi, V. (2011). Does personality traits influence the choice of investment?. The IUP Journal of Behavioral Finance, 8(2), 47-57.

Costa, P. T., \& McCrae, R. R. (1992). Normal personality assessment in clinical practice: The NEO personality inventory. Psychological Assessment, 4(1), 5-13.

Durand, R. B., Newby, R., \& Sanghani, J. (2008). An intimate portrait of the individual investor. The Journal of Behavioral Finance, 9(4), 193-208.

Enescu, M., \& Enescu, M. (2009). Psihonomy - psychology investors. Annals of the University of Petrosani, Economics, 9(1), 249-252.

Garman, E. T., \& Forgue, R. E. (1997). Personal finance (5th ed.). Boston, MA: Houghton Mifflin.

Gunkel, M., Sclaegel, C., Langella, I. A., \& Peluchette, J. V. (2010). Personality and career deciciveness: An international empirical compirical comparison of business student's carrer planning. Personnel Review, 39(4), 503-524.

Hai, N. D. T. (2015). Mô hình tính cách năm yếu tố [Five Factor Model]. Retrieved October 20, 2018, from https://beautifulmindvn.com/2015/11/11/mo-hinh-tinh-cach-5-yeu-to-fivefactor-model/.

Hira, T. K. (2012). Promoting sustainable financial behaviour: Implications for education and research. International Journal of Customer Studies, 36(5), 502-507.

Hoch, S. J., \& Loewenstein, G. F. (1991). Time-inconsistent preferences and customer selfcontrol. Journal of Customer Research, 17(4), 492-507.

Joo, S., \& Grable, J. E. (2004). An exploratory framework of the factors that influence financial satisfaction. Journal of Family and Economic Issues, 25(1), 25-50.

Keller, C., \& Siegrist, M. (2006). Investing in stocks: The influence of financial risk attitude and values-related money and stock market attitudes. Journal of Economic Psychology, 27(2), 285-303.

Kiev, A. (2003). The psychology of risk: Mastering market uncertainty. Hoboken, NJ: John Wiley \& Sons.

Lam Phong (2019). Phát triển sản phẩm mới, thu hút thêm nhà đầu tư [Develop new products, attract more investors]. Retrieved October 22, 2018, from https://tinnhanhchungkhoan.vn/ chung-khoan/phat-trien-san-pham-moi-thu-hut-them-nha-dau-tu-302913.html.

Lim, K. L., Soutar, G. N., \& Lee, J. A. (2013). Factors affecting investment intentions: A consumer behaviour perspective. Journal of Financial Services Marketing, Nature Publishing Group, 18(4), 301-315.

Martins, N. (2002). A model for managing trust. International Journal of Manpower, 23(8), 754-769.

Mayfield, C., Perdue, G., \& Wooten, K. (2008). Investment management and personality type. Financial Services Review, 17(3), 219-234.

McCrae, R., \& Costa, P. T. (1997). Personality trait structure as a human universal. American Psychologist, 52(5), 509-516.

McCrae, R. R., \& Sutin, A. R. (2009). Openness to experience. In M. R. Leary \& R. H. Hoyle (Eds.), Handbook of individual differences in social behavior (pp. 257-273). NewYork, NY: Guilford Press. 
Miller, R. K., \& Washington, K. (2009). Consumer behavior. Atlanta, GE: Richard K. Miller \& Associates.

Mothersbaugh, D. L., \& Hawkins, D. I. (2016). Consumer behavior: Building marketing strategy. New York, NY: McGraw-Hill.

Nadan, T., \& Saurabh, K. (2016). Big-five personality traits, financial risk attitude and investmnet intentions: Study on Generation Y. International Journal of Business Forecasting and Marketing Intelligence, 2(2), 128-150.

Nga, J., \& Yien, L. (2013). The influence of personality trait and demographics on financial decision making among Generation Y. Young Consumers, 14(3), 230-243.

Nguyen, T. D., \& Nguyen, T. T. M. (2011). Nghiên cứu khoa học Marketing: Úng dụng mô hình cấu trúc tuyến tính SEM [Marketing science research: Applying SEM linear structure model]. Ho Chi Minh, Vietnam : Nhà xuất bản Đại Học Quốc Gia Tp.HCM.

Nielsen. (2016). Mở khoá thế hệ Millennials tại Việt Nam [Unlock the Millennials generation in Vietnam]. Retrieved October 23, 2018, from https://www.nielsen.com/vn/vi/insights/ report/2016/unlocking-millennials-vietnam/

Oehler, A., Wendt, S., Wedlich, F., \& Horn, M. (2016). Investors' personality influences investment decisions: Experimental evidence on extraversion and neuroticism. Journal of Behavioral Finance, 19(1), 30-48.

Pan, C. H., \& Statman, M. (2013). Investor personality in investor questionnaires. Journal of Investment Consulting, 14(1), 48-56.

Sadi, R., Asl, H. G., Rostami, M. R., Gholipour, A., \& Gholipour, F. (2011). Behavioural finance: The explanation of investors' personality and perceptual biases effects on financial decisions. International Journal of Economics and Finance, 3(5), 234-241.

Sadiq, M. N., \& Khan, R. A. A. (2019). Impact of personality traits on investment intention: The mediating role of risk behaviors and the moderating role of financial literacy. Journal of Finance \& Economics Research, 4(1), 1-18.

Sages, R. A., \& Grable, J. E. (2010). Financial numeracy, net worth, and financial management skills: Client characteristics that differ based on financial risk tolerance. Journal of Financial Service Professionals, 64(6), 57-65.

Tổng cục thống kê. (2019). Tình hình kinh tế - xã họi 6 tháng đầu năm 2019 [Socio-economic situation in the first 6 months of 2019]. Retrieved October 25, 2018, from https://www.gso.gov.vn/default.aspx?tabid=621\&ItemID=19226

Tversky, A., \& Kahneman, D. (1974). Judgment under uncertainty: Heuristics and biases. Science, 185(4157), 1124-1131.

Weller, J. A., \& Tikir, A. (2011). Predicting domain-specific risk taking with the HEXACO personality structure. Journal of Behavioral Decision Making, 24(2), 180-201.

Xiao, J., Collins, M., Ford, M., Keller, P., Kim, J., \& Robles, B. (2010). A review of financial behavior research: Implications for financial education. Retrieved October 27, 2018, from https://dokumen.tips/documents/a-review-of-financial-behavior-research-review-offinancial-behavior-research.html

Zhao, H., \& Seibert, S. (2006). The Big Five personality dimensions and entrepreneurial status: A meta-analytical review. Journal of Applied Psychology, 91, 259-271. 